\title{
Partial Slip Impact on Double Diffusive Convection Flow of Magneto-Carreau Nanofluid through Inclined Peristaltic Asymmetric Channel
}

\author{
Safia Akram (D, ${ }^{1}$ Maria Athar, ${ }^{2}$ Khalid Saeed, ${ }^{3}$ Taseer Muhammad $\mathbb{D},{ }^{4}$ and Mir Yasir Umair ${ }^{1}$ \\ ${ }^{1}$ MCS, National University of Sciences and Technology, Islamabad 44000, Pakistan \\ ${ }^{2}$ Department of Mathematics, National University of Modern Languages, Islamabad 44000, Pakistan \\ ${ }^{3}$ Department of Mathematics, COMSATS University Islamabad, Islamabad 44000, Pakistan \\ ${ }^{4}$ Department of Mathematics, College of Sciences, King Khalid University, Abha 61413, Saudi Arabia
}

Correspondence should be addressed to Taseer Muhammad; taseer_qau@yahoo.com

Received 12 July 2021; Revised 1 August 2021; Accepted 1 November 2021; Published 24 November 2021

Academic Editor: Mohammad Yaghoub Abdollahzadeh Jamalabadi

Copyright (C) 2021 Safia Akram et al. This is an open access article distributed under the Creative Commons Attribution License, which permits unrestricted use, distribution, and reproduction in any medium, provided the original work is properly cited.

The significance of partial slip on double diffusive convection on magneto-Carreau nanofluid through inclined peristaltic asymmetric channel is examined in this paper. The two-dimensional and directional flow of a magneto-Carreau nanofluid is mathematically described in detail. Under the lubrication technique, the proposed model is simplified. The solutions of extremely nonlinear partial differential equations are calculated using a numerical technique. Graphical data are displayed using Mathematica software and Matlab to examine how temperature, pressure rise, concentration, pressure gradient, velocity profile, nanoparticle volume fraction, and stream functions behave on emerging parameters. It is noticed that as the velocity slip parameter is increased, the axial velocity at the channel's center increases. Additionally, near the boundary, opposite behavior is observed. The temperature, concentration, and nanoparticle profile drops by increasing thermal slip, concentration slip, and nanoparticle slip parameter.

\section{Introduction}

Greek word "peristaltikos" is the origin of the word "peristalsis" that refers to being clasped and compressed. It is further employed to refer to a progressive contracting wave within a tube which may have a variable cross-sectional area. It is utilized by the bodies in physiology, to push and blend the guts inside a tube such as in uretra and other sorts of glandular vessels. The same principle is used by the roller and finger pumping devices. The theory of peristaltic transport has been deployed by multiple industries on different applications that may include sanitary ducts, blood pumping devices in the lungs. Ever since the most initial research on this topic by Latham [1], few other studies based on numerical models and experiments have also been reported under multiple conditions.
In the recent times, the researchers in the domain of physiology have experienced a peristaltic kind of motion by the intrauterine duct flows. These are caused by myometrial contractions in both symmetric and asymmetric directions. Pozrikidis [2] developed a technique that was based on integral methods to further explore the peristaltic ducts in channels for the Stokes flow conditions to comprehend the process of fluid dynamics. He investigated the patterns and mean flowing rates caused by the amplitude and phase once the walls were deformed. More experiments were done by Eytan et al. [3] to characterize contractions in women who were not pregnant and found those complications as those were of different amplitudes and with a wide range of frequencies with variable wavelengths. There has been an identification that uterine cavity's cross section breadth tends to increase to the fundus, and it does not occlude while 
contracting. Similarly, Eytan and Elad [4] managed to develop a model in $2 \mathrm{D}$ channels where wave trains tend to move with independence on the upper walls as well as the lower ones. The orientations have been deployed to further perform evaluations in nonpregnant women's uterus. Calculations have been done to further calculate possible particle movements to better comprehend the process an embryo goes through. Mishra and Ramachandra Rao [5] further investigated the peristaltic transport for Newtonian fluids.

The MHD flows in a channel holds much of importance with linkage to specific concerns related to the mobility of conductive fluids such as blood. This brings a need for research based on theory for the operational MHD compressor. Stud et al. [6] investigated the effects of a changing magnetic field on blood flowing channels. They managed to identify the fact that suitable field can accelerate the speed of the blood in the channel. Srivastava and Agarwal [7] studied other aspects such as after considering blood as conducting channel having a feature to suspend red blood cells in the plasma. Further studies [8-12] have also investigated other aspects related to MHD flows on peristalsis pumping.

These days, nanotechnology is revolutionizing industrial era in the current century. For the same reason, many researchers have directed their work on modeling of such thermal conductivities and have investigated multiple nanofluids having different viscosities. Such fluids have suspended nanoparticles which are generally made of different metals, oxides, or carbon-based nanotubes. Most common ones include water, oil, and toluene. Choi [13] might have been the first researcher to coin the term nanofluid, where he mentioned that heat transfer mechanism is going to be most beneficial applications of the nanofluids. Further in [14], he explained that after adding a very meager number of nanoparticles to basic liquids, thermal conduction can be increased approximately double. Similarly, Masuda et al. [15], Lee et al. [16], Xuan and Li [17], and Xuan and Roetzel [18] showed the same enhancements by more than $20 \%$. Therefore, for heat transfer mechanisms, nanofluids can be taken up as an interesting replacement [17]. In the recent times, studies have been done for nanofluids with peristalsis as the importance of this domain linked with biosciences and chemical and mechanical engineering cannot be undermined. Such mentions are referred as [19-23].

In many industrial applications and engineering processes such as central receivers run on solar energy for creating potential through wind, cooling processes of electrical apparatus have collective forced and free convection in them. Transfer mechanism of heat and masses has effects on each other which also can yield cross-diffusion influences. The delta between the temperatures can generate mass transferring mechanism termed as Soret effect. On the contrary, when there is a heat transfer, and the difference causes an effect on the concentration gradient which is called the Dufour effect. Akram et al. [24] performed analysis in the existence of a tilted magnetic field as there are plenty of applications which are linked with peristaltic flows with double diffusion. Exact results can be acquired for a relatively new domain of nanoparticles, field of temperature, the concentration field, pressure rise, and the pressure gradient while considering the extent restrictions of longwave and a reduced Reynolds number. Authors in [25] have investigated the peristaltic flows that are induced by double diffusive convection naturally. This was to acquire analysis in an asymmetric porous channel. Current available literature studies on peristaltic flows with double diffused convection are available in references [26-29].

The no-slip conditions are used in all of the abovementioned references. In some cases, there is surely a chance that a partial slip may happen between the fluids and the surface in motion. There are recorded instances when the fluids are particulate like there is emulsion or suspension [30]. In all these instances, boundary conditions are well explained by Navier condition [31], in which the proportionality is held between the relative slip and the local stress. Research on the effects on such slips on the peristaltic mobility has been stated in the literature [32-36].

Considering the significance of the available and discussed literature and the applications linked with mixed convection in these peristaltic ducts, researchers have transformed their approaches and attention towards the theory related to double diffusion that have Carreau fluids as a fundamental fluid having slip boundaries. There is a strong chance that this investigation will head in the best manner for using the acquired data most efficiently. All the equations related to momentum, energies, and the concentration were required to be modelled with the suited physical settings such as lower wavenumbers and the Reynolds number. Equations have been solved numerically. All the results are depicted using graphs and further discussed.

\section{Mathematical Formulation}

We are in the process of investigating the incompressible trapping peristaltic flow of Carreau nanofluids in the $2 \mathrm{D}$ channel having $\widetilde{d}_{1}+\widetilde{d}_{2}$ width. The coordinates are selected in such a way that the channel's center is placed along the horizontal axis while vertical axis keeps the cross-sectional area. On the wall end, the speed of sinusoidal wave train stays persistent and does not change over time. Temperature, concentration of the solvents, and the nanoparticles of lower and the upper walls have also been considered as $\left(T_{1}, T_{0}\right)$, $\left(C_{1}, C_{0}\right)$, and $\left(\Theta_{1}, \Theta_{0}\right)$ respectively. The channel is inclined at an angle $\zeta$. A persistent magnetic field is tested with angle $\beta$. In all this, the electrical field is taken as minimal as nil while Reynolds number is chosen as a low value that results in minimized or almost negligible induced magnetic field while comparing with the applied one. The mathematical expression for the surface of a wall is as follows [5]:

$$
\begin{aligned}
& Y=H_{1}=\tilde{d}_{1}+\tilde{a}_{1} \cos \left[\frac{2 \pi}{\lambda}(X-c t)\right], \\
& Y=H_{2}=-\widetilde{d}_{2}-\tilde{b}_{1} \cos \left[\frac{2 \pi}{\lambda}(X-c t)+\varphi\right],
\end{aligned}
$$

where $\lambda, t, c,\left(\tilde{a}_{1}, \tilde{b}_{1}\right)$, and $\left(\tilde{d}_{1}, \tilde{d}_{2}\right)$ are wavelength, time, speed of wave, wave amplitudes, and channel thickness, 
respectively. The range of phase difference $\varphi$ is $0 \leq \varphi \leq \pi$, with $\varphi=0$ representing a symmetric channel without a phase wave and $\varphi=\pi$ representing a channel with a phase wave. Furthermore, $\widetilde{a}_{1}, \widetilde{d}_{1}, \widetilde{b}_{1}, \widetilde{d}_{2}$, and $\varphi$ meet the following condition: $\widetilde{a}_{1}^{2}+\widetilde{b}_{1}^{2}+2 \widetilde{a}_{1} \vec{b}_{1} \cos \varphi \leq\left(\widetilde{d}_{1}+\widetilde{d}_{2}\right)^{2}$. The field of velocity for 2D channel flow is $V=(U(X, Y, t)$, $V(X, Y, t), 0)$.

The expression of the Carreau nanofluid stress tensor is as follows [13]:

$$
\mathbf{S}=-\left[\mu_{\infty}+\left(\mu_{0}-\mu_{\infty}\right)\left(1+(\Gamma \dot{\xi})^{2}\right)\right]^{(n-1) / 2} \widetilde{\mathbf{A}},
$$

where $\Gamma, \mu_{\infty}$, and $\mu_{0}$ denotes material constant, infinite viscosity, and zero shear rate viscosity, respectively. Also in the case where $\mu_{\infty}=0$, the fundamental relation of $S$ is

$$
\mathbf{S}=-\left[\mu_{0}\left(1+(\Gamma \dot{\xi})^{2}\right)\right]^{(n-1) / 2} \widetilde{\mathbf{A}}
$$

The second invariant tensor $\dot{\xi}$ and first Rivlin-Ericksen tensor $\widetilde{A}$ are defined as

$$
\begin{aligned}
& \tilde{\mathbf{A}}=(\nabla \mathbf{V})+(\nabla \mathbf{V})^{*}, \\
& \dot{\xi}=\sqrt{\frac{1}{2}\left(\operatorname{trac}(\tilde{\mathbf{A}})^{2}\right)} .
\end{aligned}
$$

For $\Gamma=0$, the Carreau nanofluids are reduced to Newtonian nanofluids.

In a fixed frame, the continuity, momentum, temperature, solute concentration, and nanoparticle fraction are defined [33] as

$$
\begin{aligned}
\frac{\partial U}{\partial X}+\frac{\partial V}{\partial Y}= & 0 \\
\rho\left(\frac{\partial}{\partial t}+U \frac{\partial}{\partial X}+V \frac{\partial}{\partial Y}\right) U= & -\frac{\partial p}{\partial X}-\frac{\partial S_{X X}}{\partial X}-\frac{\partial S_{X Y}}{\partial Y}-\sigma B_{0}^{2} \cos \beta(U \cos \beta-V \sin \beta) \\
& +\rho g \sin \zeta+g\left\{\left(1-\Theta_{0}\right) \rho_{f 0}\left\{\beta_{T}\left(T-T_{0}\right)+\beta_{C}\left(C-C_{0}\right)\right\}-\left(\rho_{p}-\rho_{f 0}\right)\left(\Theta-\Theta_{0}\right)\right\} \\
\rho\left(\frac{\partial}{\partial t}+U \frac{\partial}{\partial X}+V \frac{\partial}{\partial Y}\right) V= & -\frac{\partial p}{\partial Y}-\frac{\partial S_{Y X}}{\partial X}-\frac{\partial S_{Y Y}}{\partial Y}-\rho g \cos \zeta \\
& +\sigma B_{0}^{2} \sin \beta(U \cos \beta-V \sin \beta) \\
(\rho c)_{f}\left(\frac{\partial T}{\partial t}+U \frac{\partial T}{\partial X}+V \frac{\partial T}{\partial Y}\right)= & k\left(\frac{\partial^{2} T}{\partial X^{2}}+\frac{\partial^{2} T}{\partial Y^{2}}\right)+(\rho c)_{p}\left\{D_{B}\left(\frac{\partial \Theta}{\partial X} \frac{\partial T}{\partial X}+\frac{\partial \Theta}{\partial Y} \frac{\partial T}{\partial Y}\right)\right. \\
& \left.\cdot\left(\frac{D_{T}}{T_{0}}\right)\left[\left(\frac{\partial T}{\partial X}\right)^{2}+\left(\frac{\partial T}{\partial Y}\right)^{2}\right]\right\}+D_{T C}\left(\frac{\partial^{2} C}{\partial X^{2}}+\frac{\partial^{2} C}{\partial Y^{2}}\right) \\
\left(\frac{\partial C}{\partial t}+U \frac{\partial C}{\partial X}+V \frac{\partial C}{\partial Y}\right)= & D_{s}\left(\frac{\partial^{2} C}{\partial X^{2}}+\frac{\partial^{2} C}{\partial Y^{2}}\right)+D_{T C}\left(\frac{\partial^{2} T}{\partial X^{2}}+\frac{\partial^{2} T}{\partial Y^{2}}\right) \\
\left(\frac{\partial \Theta}{\partial t}+U \frac{\partial \Theta}{\partial X}+V \frac{\partial \Theta}{\partial Y}\right)= & D_{B}\left(\frac{\partial^{2} \Theta}{\partial X^{2}}+\frac{\partial^{2} \Theta}{\partial Y^{2}}\right)+\left(\frac{D_{T}}{T_{0}}\right)\left(\frac{\partial^{2} T}{\partial X^{2}}+\frac{\partial^{2} T}{\partial Y^{2}}\right)
\end{aligned}
$$

where the Carreau fluid stress tensor in component form is written as

$$
\begin{aligned}
& S_{X X}=-2 \mu_{0}\left(1+\frac{n-1}{2}(\Gamma \dot{\xi})^{2}\right) \frac{\partial U}{\partial X} \\
& S_{X Y}=-\mu_{0}\left(1+\frac{n-1}{2}(\Gamma \dot{\xi})^{2}\right)\left(\frac{\partial U}{\partial Y}+\frac{\partial V}{\partial X}\right), \\
& S_{Y Y}=-2 \mu_{0}\left(1+\frac{n-1}{2}(\Gamma \dot{\xi})^{2}\right) \frac{\partial V}{\partial Y} \\
& \dot{\xi}^{2}=2\left(\frac{\partial U}{\partial X}\right)^{2}+\left(\frac{\partial U}{\partial Y}+\frac{\partial V}{\partial X}\right)^{2}+2\left(\frac{\partial V}{\partial Y}\right)^{2} .
\end{aligned}
$$

In the laboratory frame $(X, Y)$, the flow is unsteady, although the motion is steady in the coordinate system $(x, y)$. The transformation from one frame of reference to the other is described by

$$
\begin{aligned}
u & =U-c, \\
v & =V, \\
x & =X-c t, \\
y & =Y, \\
p(x, y) & =P(X, Y, t) .
\end{aligned}
$$

Define 


$$
\begin{aligned}
& \bar{x}=\frac{x}{\lambda}, \\
& \bar{y}=\frac{y}{\tilde{d}_{1}}, \\
& \bar{v}=\frac{v}{c}, \\
& \bar{u}=\frac{u}{c}, \\
& \delta=\frac{\widetilde{d}_{1}}{\lambda}, \\
& d=\frac{\widetilde{d}_{2}}{\tilde{d}_{1}}, \\
& \bar{t}=\frac{c t}{\lambda}, \\
& h_{2}=\frac{H_{2}}{\tilde{d}_{2}} \text {, } \\
& h_{1}=\frac{H_{1}}{\widetilde{d}_{1}} \text {, } \\
& b=\frac{\widetilde{b}_{1}}{\widetilde{d}_{1}}, \\
& \bar{p}=\frac{\tilde{d}_{1}^{2} p}{\mu_{0} c \lambda}, \\
& a=\frac{\widetilde{a}_{1}}{\tilde{d}_{1}} \\
& \operatorname{Pr}=\frac{(\rho c)_{f} v}{k}, \\
& \operatorname{Re}=\frac{\rho_{f} c \tilde{d}_{1}}{\mu_{0}}, \\
& v=\frac{\mu_{0}}{\rho_{f}}, \\
& \text { Le }=\frac{v}{D_{s}} \text {, } \\
& \operatorname{Ln}=\frac{v}{D_{B}} \text {, } \\
& u=\frac{\partial \psi}{\partial y}, \\
& v=-\delta \frac{\partial \psi}{\partial x}, \\
& \theta=\frac{T-T_{0}}{T_{1}-T_{0}}, \\
& \gamma=\frac{C-C_{0}}{C_{1}-C_{0}}, \\
& \Omega=\frac{\Theta-\Theta_{0}}{\Theta_{1}-\Theta_{0}}, \\
& \mathrm{We}=\frac{c \Gamma}{\widetilde{d}_{1}},
\end{aligned}
$$

$$
\begin{aligned}
\bar{S}_{x x} & =\frac{S_{x x} \lambda}{\mu_{0} c}, \bar{S}_{x y}=\frac{S_{x y} \tilde{d}_{1}}{\mu_{0} c}, \\
\bar{S}_{y y} & =\frac{S_{y y} \widetilde{d}_{1}}{\mu_{0} c}, \\
N_{C T} & =\frac{D_{C T}\left(T_{1}-T_{0}\right)}{\left(C_{1}-C_{0}\right) D_{s}}, \\
N_{T C} & =\frac{D_{C T}\left(C_{1}-C_{0}\right)}{k\left(T_{1}-T_{0}\right)}, \\
G_{r t} & =\frac{g \widetilde{d}_{1}^{2}\left(1-\Theta_{0}\right)\left(T_{1}-T_{0}\right) \rho_{f} \beta_{T}}{\mu_{0} c}, \\
G_{r c} & =\frac{g\left(1-\Theta_{0}\right) \rho_{f} \beta_{c}\left(C_{1}-C_{0}\right) \tilde{d}_{1}^{2}}{\mu_{0} c}, \\
G_{r F} & =\frac{g\left(\rho_{p}-\rho_{f}\right)\left(\Theta_{1}-\Theta_{0}\right) \tilde{d}_{1}^{2},}{\mu_{0} c} \\
N_{t} & =\frac{(\rho c)_{p} D_{T}\left(T_{1}-T_{0}\right)}{T_{0} k}, \\
N_{b} & =\frac{(\rho c)_{p} D_{B}\left(\Theta_{1}-\Theta_{0}\right)}{k}, \\
\operatorname{Fr} & =\frac{c^{2}}{g \widetilde{d}_{1}}, \\
M & =\sqrt{\frac{\sigma}{\mu_{0}} B_{0} \widetilde{d}_{1} .}
\end{aligned}
$$

Using equations (12) and (13), the equations (5)-(11) become

$$
\begin{aligned}
\operatorname{Re} \delta\left(\psi_{y} \psi_{x y}-\psi_{x} \psi_{y y}\right)= & -\frac{\partial p}{\partial x}-\delta \frac{\partial S_{x x}}{\partial x}-\frac{\partial S_{x y}}{\partial y}-M^{2} \cos \beta \\
& \cdot\left(\left(\psi_{y}+1\right) \cos \beta+\psi_{x} \delta \sin \beta\right) \\
& +\frac{\operatorname{Re}}{\mathrm{Fr}} \sin \zeta+G_{r t} \theta+G_{r c} \gamma-G_{r F} \Omega,
\end{aligned}
$$

$\operatorname{Re} \delta^{3}\left(\psi_{x} \psi_{x y}-\psi_{y} \psi_{x x}\right)=-\frac{\partial p}{\partial y}-\delta^{2} \frac{\partial S_{x y}}{\partial x}-\delta \frac{\partial S_{y y}}{\partial y}-\delta \frac{\operatorname{Re}}{\operatorname{Fr} \cos \zeta}$

$+M^{2} \delta \sin$

$\cdot \beta\left(\left(\psi_{y}+1\right) \cos \beta+\psi_{x} \delta \sin \beta\right)$,

$$
\begin{aligned}
\operatorname{Re} \operatorname{Pr} \delta\left(\psi_{y} \theta_{x}-\psi_{x} \theta_{y}\right)= & \left(\theta_{y y}+\delta^{2} \theta_{x x}\right)+N_{T C}\left(\delta^{2} \gamma_{x x}+\gamma_{y y}\right) \\
& +N_{b}\left(\delta^{2} \theta_{x} \Omega_{x}+\theta_{y} \Omega_{y}\right) \\
& +N_{t}\left(\delta^{2}\left(\theta_{x}\right)^{2}+\left(\theta_{y}\right)^{2}\right),
\end{aligned}
$$

$\operatorname{Re} \delta \operatorname{Le}\left(\psi_{y} \gamma_{x}-\psi_{x} \gamma_{y}\right)=\left(\delta^{2} \gamma_{x x}+\gamma_{y y}\right)+N_{C T}\left(\delta^{2} \theta_{x x}+\theta_{y y}\right)$, 
$\operatorname{Re} \delta \operatorname{Ln}\left(\psi_{y} \Omega_{x}-\psi_{x} \Omega_{y}\right)=\left(\delta^{2} \Omega_{x x}+\Omega_{y y}\right)+\frac{N_{t}}{N_{b}}\left(\delta^{2} \theta_{x x}+\theta_{y y}\right)$.

The components of the stresses are represented in nondimensional form as

$$
\begin{aligned}
S_{x x} & =-2\left(1+\frac{n-1}{2} \mathrm{We}^{2} \dot{\xi}^{2}\right) \frac{\partial^{2} \psi}{\partial x \partial y} \\
S_{x y} & =-\left(1+\frac{n-1}{2} \mathrm{We}^{2} \dot{\xi}^{2}\right)\left(\frac{\partial^{2} \psi}{\partial y^{2}}-\delta^{2} \frac{\partial^{2} \psi}{\partial x^{2}}\right) \\
S_{y y} & =2 \delta\left(1+\frac{n-1}{2} \mathrm{We}^{2} \dot{\xi}^{2}\right) \frac{\partial^{2} \psi}{\partial x \partial y} \\
\dot{\xi}^{2} & =2 \delta^{2}\left(\frac{\partial^{2} \psi}{\partial x \partial y}\right)^{2}+\left(\frac{\partial^{2} \psi}{\partial y^{2}}-\delta^{2} \frac{\partial^{2} \psi}{\partial x^{2}}\right)^{2}+2 \delta^{2}\left(\frac{\partial^{2} \psi}{\partial x \partial y}\right)^{2}
\end{aligned}
$$

where $\psi, \operatorname{Pr}$ Re, $\gamma, p, \theta, \delta, \Omega$, We, Le, $N_{b}, M, N_{t}, G_{r F}, G_{r t}$, $G_{r c}, N_{C T}, N_{T C}$, and Ln denotes stream function, Prandtl number, Reynolds number, solutal (species) concentration in dimensionless form, pressure, dimensionless temperature, wave number, nanoparticle fraction, Weissenberg number, Lewis number, Brownian motion, Hartmann number, thermophoresis parameter, Grashof number of nanoparticle, thermal Grashof number, solutal Grashof number, Soret parameter, Dufour parameter, and nanofluid Lewis number, respectively.

Using estimations of long wavelength $\delta \ll 1$ and low Reynolds number, equations (14)-(22) are reduced to the form as

$$
\begin{aligned}
\frac{\partial p}{\partial x}= & \frac{\partial}{\partial y}\left[\left(1+\frac{n-1}{2} \mathrm{We}^{2}\left(\frac{\partial^{2} \psi}{\partial y^{2}}\right)^{2}\right) \frac{\partial^{2} \psi}{\partial y^{2}}\right] \\
& -M^{2} \cos ^{2} \beta\left(\Psi_{y}+1\right) \\
& +\frac{\operatorname{Re}}{\mathrm{Fr}} \sin \zeta+G_{r t} \theta+G_{r c} \gamma-G_{r F} \Omega \\
-\frac{\partial p}{\partial y}= & 0, \\
\frac{\partial^{2} \theta}{\partial y^{2}}+ & N_{T C} \frac{\partial^{2} \gamma}{\partial y^{2}}+N_{b}\left(\frac{\partial \theta}{\partial y} \frac{\partial \Omega}{\partial y}\right)+N_{t}\left(\frac{\partial \theta}{\partial y}\right)^{2}=0 \\
\frac{\partial^{2} \gamma}{\partial y^{2}}+ & N_{C T} \frac{\partial^{2} \theta}{\partial y^{2}}=0 \\
\frac{\partial^{2} \Omega}{\partial y^{2}}+ & \frac{N_{t}}{N_{b}} \frac{\partial^{2} \theta}{\partial y^{2}}=0
\end{aligned}
$$

After removing pressure from equations (23) and (24), the governing equation for stream function is

$$
\begin{aligned}
& \frac{\partial^{2}}{\partial y^{2}}\left[\left(1+\frac{n-1}{2} \mathrm{We}^{2}\left(\frac{\partial^{2} \psi}{\partial y^{2}}\right)^{2}\right) \frac{\partial^{2} \psi}{\partial y^{2}}\right]-M^{2} \cos ^{2} \beta \frac{\partial^{2} \psi}{\partial y^{2}} \\
& +G_{r t} \frac{\partial \theta}{\partial y}+G_{r c} \frac{\partial \gamma}{\partial y}-G_{r F} \frac{\partial \Omega}{\partial y}=0 .
\end{aligned}
$$

The mean flow $Q$ is calculated in dimensionless form as follows:

$$
Q=1+F+d
$$

where

$$
F=\int_{h_{2}(x)}^{h_{1}(x)} \frac{\partial \psi}{\partial y} \mathrm{~d} y=\psi\left(\left(h_{1}(x)\right)-\psi\left(h_{2}(x)\right)\right),
$$

here

$$
\begin{aligned}
& h_{1}(x)=1+a \cos 2 \pi x, \\
& h_{2}(x)=-d-b \cos (2 \pi x+\varphi) .
\end{aligned}
$$

The foregoing system of PDE's (25)-(28) will be solved under the following nondimensional boundary conditions:

$$
\begin{aligned}
\psi & =\frac{F}{2}, \\
\frac{\partial \Psi}{\partial y} & =-\eta_{1} S_{x y}-1 \quad \text { on } y=h_{1}(x), \\
\psi & =-\frac{F}{2}, \\
\frac{\partial \Psi}{\partial y} & =\eta_{1} S_{x y}-1 \quad \text { on } y=h_{2}(x), \\
\theta+\eta_{2} \frac{\partial \theta}{\partial y} & =0, \quad \text { on } y=h_{1}(x), \\
\theta-\eta_{2} \frac{\partial \theta}{\partial y} & =1, \quad \text { on } y=h_{2}(x), \\
\gamma+\eta_{3} \frac{\partial \gamma}{\partial y} & =0, \quad \text { on } y=h_{1}(x), \\
\gamma-\eta_{4} \frac{\partial \Omega}{\partial y} & =1, \quad \text { on } y=h_{2}(x) . \\
\Omega+\eta_{4} \frac{\partial \Omega}{\partial y} & =0, \quad \text { on } y=h_{1}(x), \\
\gamma-h_{2}(x), & \text { on } y=1,
\end{aligned}
$$

There are no-slip conditions if $\eta_{1}, \eta_{2}, \eta_{3}, \eta_{4}=0$ in the above conditions. 


\section{Results and Discussion}

This section depicts the mathematical and realistic consequences of the present topic under study. The systems of PDE's (23), (25)-(27), and (28) are coupled and nonlinear in nature. So, finding the exact solution to these equations is extremely difficult. As a result, the built-in command MATHEMATICA is used to calculate the numeric solution (NDSolve). To check the accuracy of the proposed numerical results and to compare our findings to the available literature, a slew of graphs was created.

3.1. Flow Characteristics. The profile of velocity under the stimulation of Hartmann number $M$, Brownian motion $N_{b}$, Weissenberg number $\mathrm{We}$, and velocity slip parameter $\eta_{1}$ is shown in Figures 1(a)-1(d). The behaviour of velocity field for increasing values of Hartmann number is plotted in Figure 1(a). We can notice that increasing $M$ tends to resist the flow, resulting in a decrease in fluid velocity. This occurs because when a magnetic field is produced, a resistive force (or "Lorentz force") is created, which operates in the opposite direction of the flow, causing the velocity field to decrease (see Figure 1(a)). It is noted in Figure 1(b)) that the magnitude of velocity distribution decreases at the left side of the channel, whereas it decreases at the right side of the channel by raising the Brownian motion parameter $N_{b}$. It is depicted in Figure 1(c) that when Weissenberg number grows, velocity will increase. However, near the channel walls behaviour is opposite. This occurs because We has a direct relationship with the time constant and an inverse relationship with the channel width. The axial velocity increases near the channel's center as the velocity slip parameter $\eta_{1}$ is raised, as seen in Figure 1(d). Furthermore, opposite behavior is found near the boundaries.

3.2. Pressure Rise and Pressure Gradient. Pumping is a hallmark aspect of peristalsis. The effects of several emergent factors on pressure rise per wavelength and pressure gradient are described in this section. Figures 2(a)-2(d) show the change in pressure rise against flow rate $Q$ for various values of the parameters $n$ (power law index), We (Weissenberg number), $M$ (Hartmann number), and $\eta_{1}$ (velocity slip parameter). From these figures, it is noted that in retrograde $(\Delta p>0, Q<0)$, peristaltic $(\Delta p>0, Q>0)$, and free $(\Delta p=0)$ pumping regions, the pressure rise increases due to the increasing values of $n$, We, $M$, and $\eta_{1}$ and whereas in copumping $(\Delta p<0, Q>0)$ region pressure rise drops due to the increasing values of $n$, We, $M$, and $\eta_{1}$. The fluctuation of axial pressure gradient for different values of the $\eta_{1}$ (velocity slip parameter), $N_{t}$ (thermophoresis parameter), $\zeta$ (inclination angle), and We (Weissenberg number) is shown in Figures 3(a)-3(d). We observe that the pressure gradient is quite modest in the larger region of the channel at $x \in[0,0.3]$ and $x \in[0.5,1.0]$, indicating that the flow can readily pass without imposing a high-pressure gradient, where a substantially bigger pressure gradient is necessary to maintain the same flux in a small region of the channel at $x \in[0.3,0.5]$, particularly for the widest region at $x=0.5$.
This is in line with the current physical situation. We also notice that as the velocity slip parameter $\eta_{1}$ is increased, the axial pressure gradient falls (see Figure 3(a)). When $N_{t}$ and $\zeta$ is increased, the pressure gradient increases (see Figures 3(b) and 3(c)). Furthermore, as seen in Figure 3(d), the magnitude value of axial pressure gradient grows as the Weissenberg number (We) increases.

\subsection{Temperature, Concentration, and Nanoparticle Volume} Fraction. This section analyses the impact of many salient parameters on temperature, concentration, and nanoparticle volume fraction. Figures 4(a)-4(c) shows the temperature profile for various values of thermal slip $\eta_{2}$ parameter, Brownian motion $N_{b}$ parameter, and Soret parameter $N_{C T}$. It is noted in Figure 4(a) that when $y \in[-0.1,0.2]$, the temperature profile drops by increasing thermal slip parameter $\eta_{2}$ whereas when $y \in[0.2,1]$ the temperature profile increases. The temperature increases by increasing Brownian motion parameter and Soret parameter (see Figures 4(b) and $4(c))$. It is because Soret parameters have a direct relationship with temperature. Furthermore, nanoparticles travel efficiently from the wall to the fluid via enhancing Brownian motion. As a result of this impact, temperature rises as $N_{b}$ and $N_{C T}$ rise. The concentration profile is shown in Figures 5(a)-5(c) for various values of the concentration slip parameter $\eta_{3}$, Soret parameter $N_{C T}$, and thermophoresis parameter $N_{t}$. It is noted in Figures 5(a) that increasing concentration slip parameter $\eta_{3}$ lowers the concentration profile in the region $y \in[-0.1,0.6]$, while raising it in the region $y \in[0.6,1]$. The concentration decreases by increasing Soret parameter $N_{C T}$ and thermophoresis parameter $N_{t}$ (see Figures 5(b) and 5(c)). It is due to the influence of random motion with micromixing and erratic collision activity of solid nanoparticles, which disperses the solid nanoparticles and so lowers the solute concentration. Figures 6(a)-6(c) show the nanoparticle fraction for various values of the nanoparticle slip parameter $\eta_{4}$, Dufour parameter $N_{T C}$, and Brownian motion parameter $N_{b}$. It is noticed in Figure 6(a) that increasing nanoparticle slip parameter $\eta_{4}$ lowers the nanoparticle profile in the region where $y \in[-0.1,0.6]$, while raising it in the region where $y \in[0.6,1]$. When the Dufour parameter $N_{T C}$ is increased, the nanoparticle fraction falls (see Figure 6(b)). It is observed in Figure 6(c) that the nanoparticle volume fraction profile grows as Brownian motion parameter increases.

3.4. Trapping. Another remarkable characteristic of peristaltic movement is trapping. It is the phenomenon of closed streamlines generating a bolus of fluid that circulates inside. Streamlines grab the fluid mass bolus and drive it forward with peristaltic waves at high flow rates and substantial occlusions. In Figures 7-10, streamlines are plotted to show the phenomenon of trapping. The behaviour of streamlines for various Weissenberg numbers is depicted in Figure 7. It is observed from these streamlines that, by raising Weissenberg numbers, the number of trapped bolus grows in the upper half of the channel while the size of trapped bolus increases in the lower half. Figure 8 depicts the streamlines 

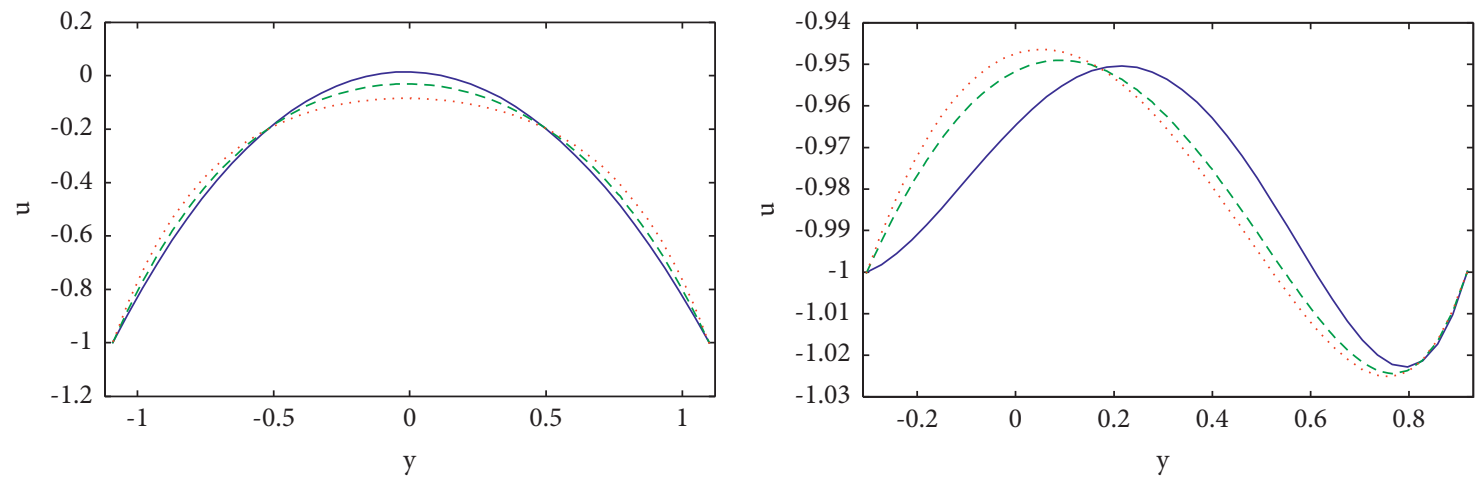

$$
\begin{aligned}
& -M=1.0 \\
& ---M=2.0 \\
& \ldots \ldots M=3.0
\end{aligned}
$$

$-\mathrm{N}_{\mathrm{b}}=0.1$

$$
--\mathrm{N}_{\mathrm{b}}=0.2
$$$$
\text { …. } \mathrm{N}_{\mathrm{b}}=0.3
$$

(a)

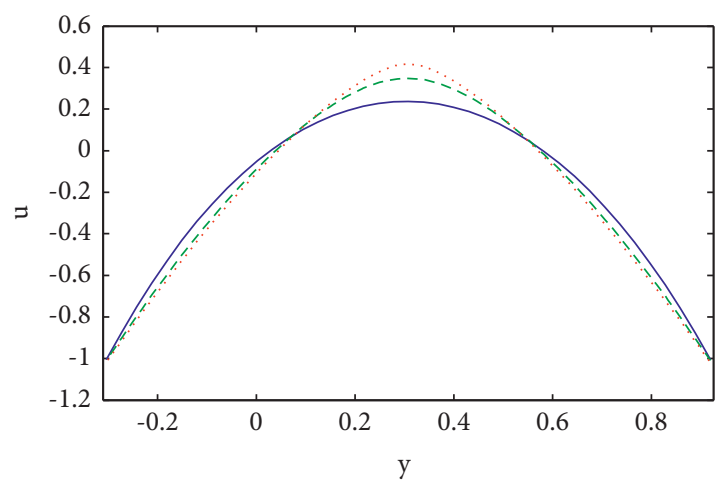

(b)

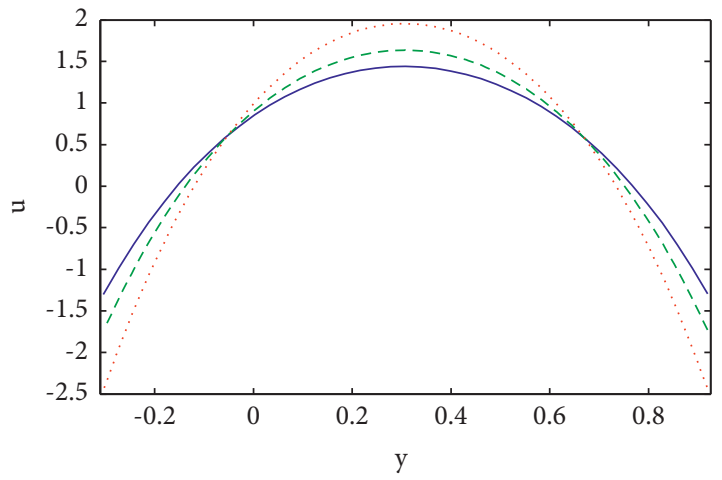

$$
\begin{aligned}
&-\mathrm{We}=0.1 \\
&--\mathrm{We}=0.5-\eta_{1}=0.05 \\
&---\eta_{1}=0.10 \\
& \cdots \cdots \mathrm{We}=0.9 \cdots \cdots \eta_{1}=0.15
\end{aligned}
$$

(c)

(d)

FIgURE 1: Impact of velocity on $M, N_{b}$, We, and $\eta_{1}$.

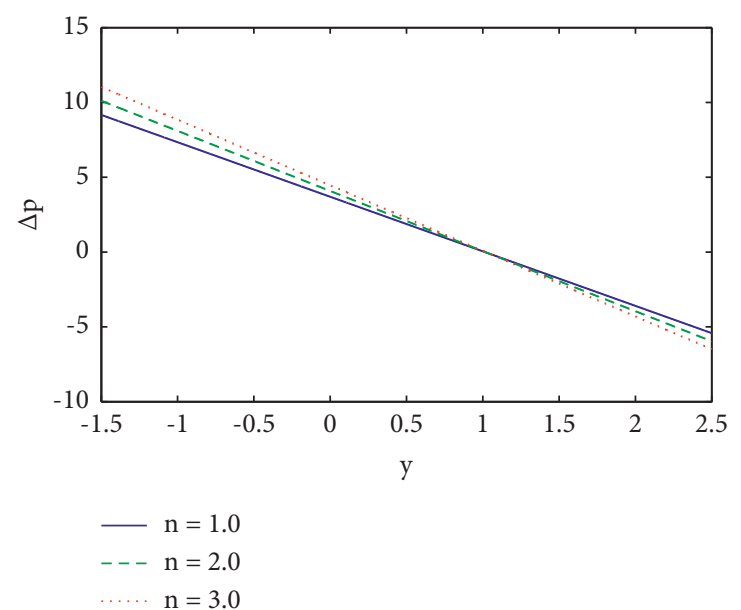

(a)

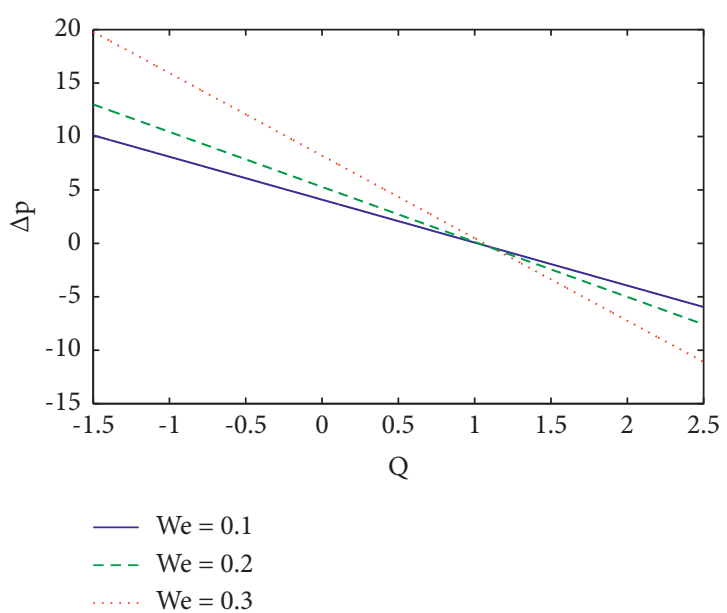

(b)

Figure 2: Continued. 


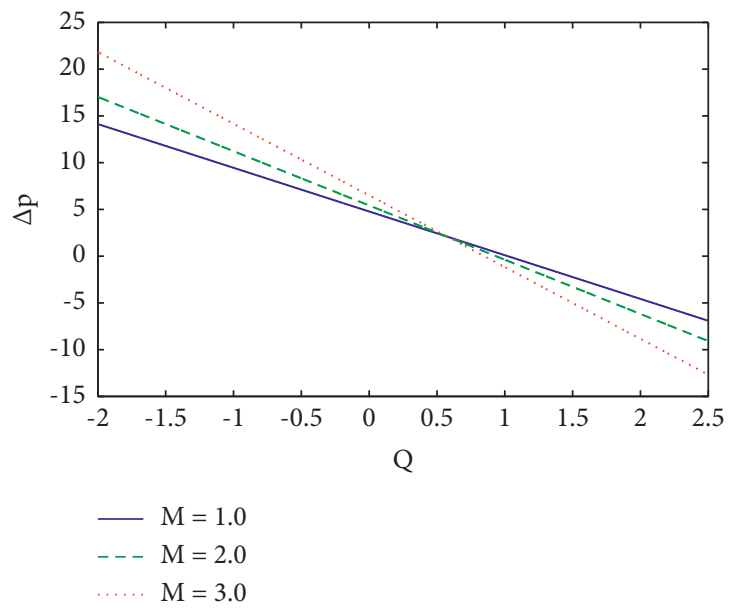

(c)

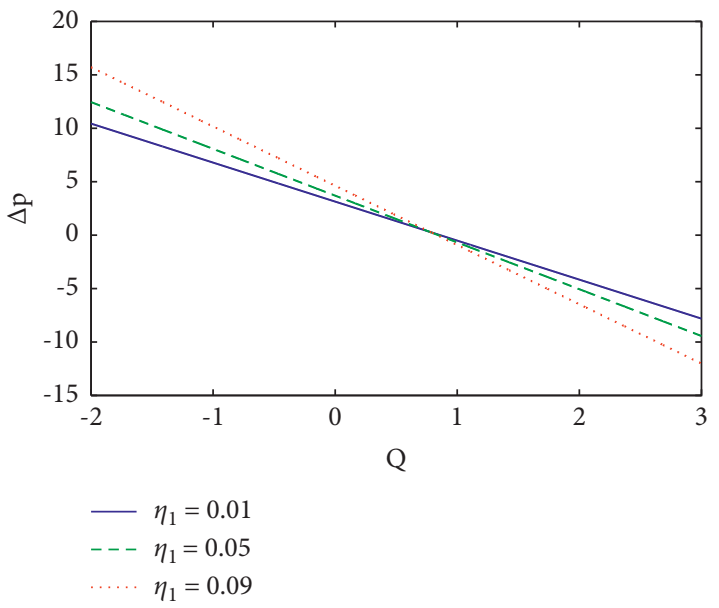

(d)

Figure 2: Impact of pressure rise on $n$, We, $M$, and $\eta_{1}$.
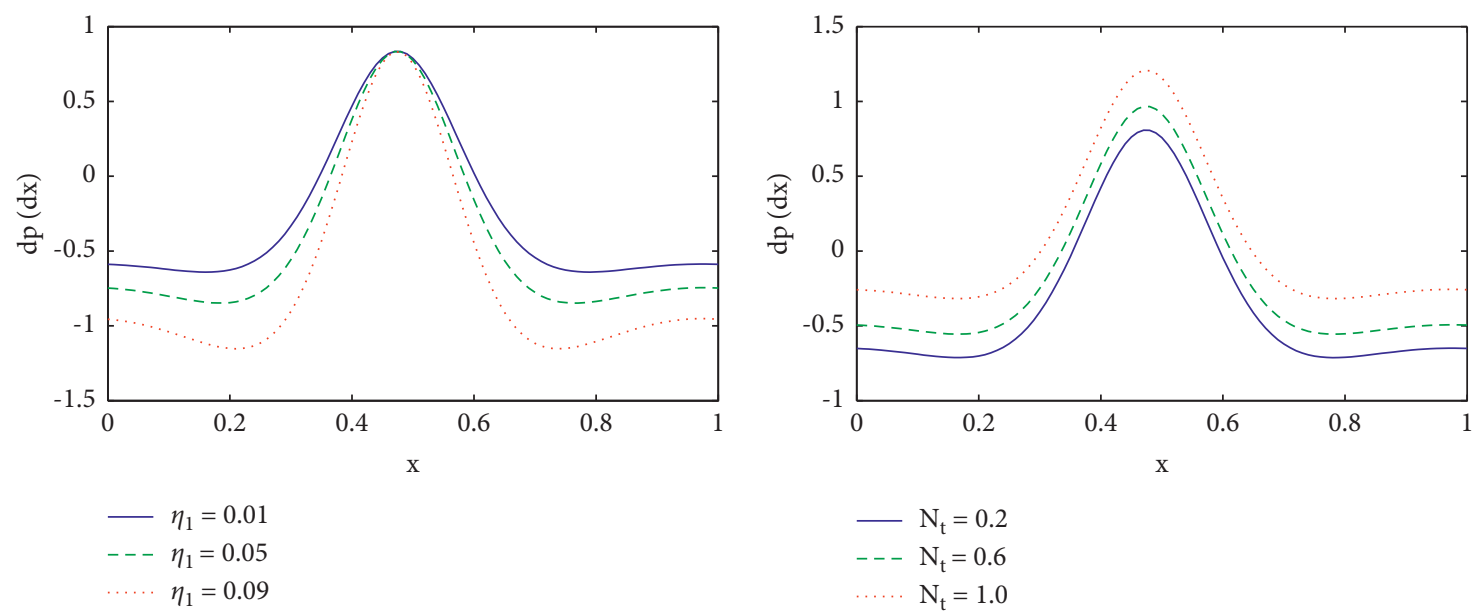

(a)

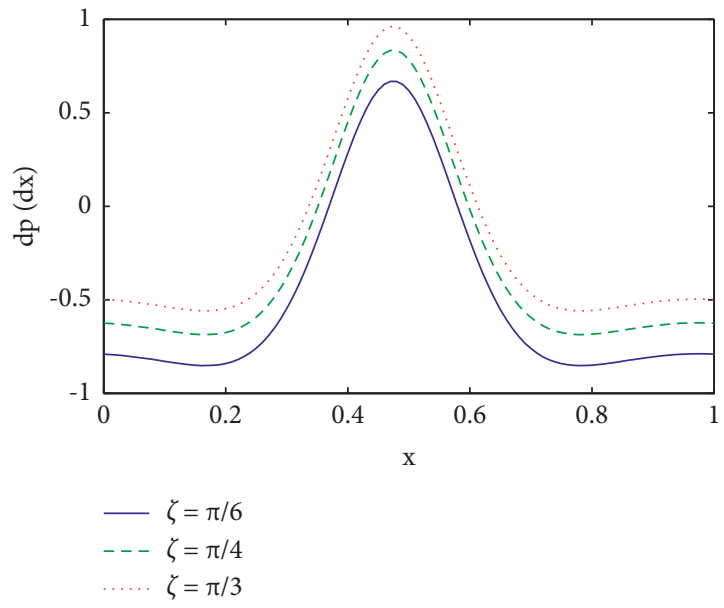

(c)

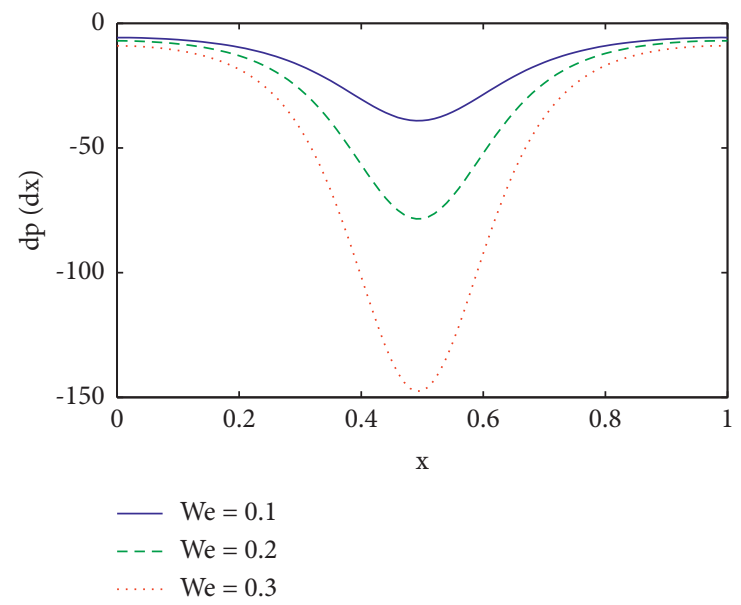

(d)

Figure 3: Impact of pressure gradient on $\eta_{1}, N_{t}, \zeta$, and We. 

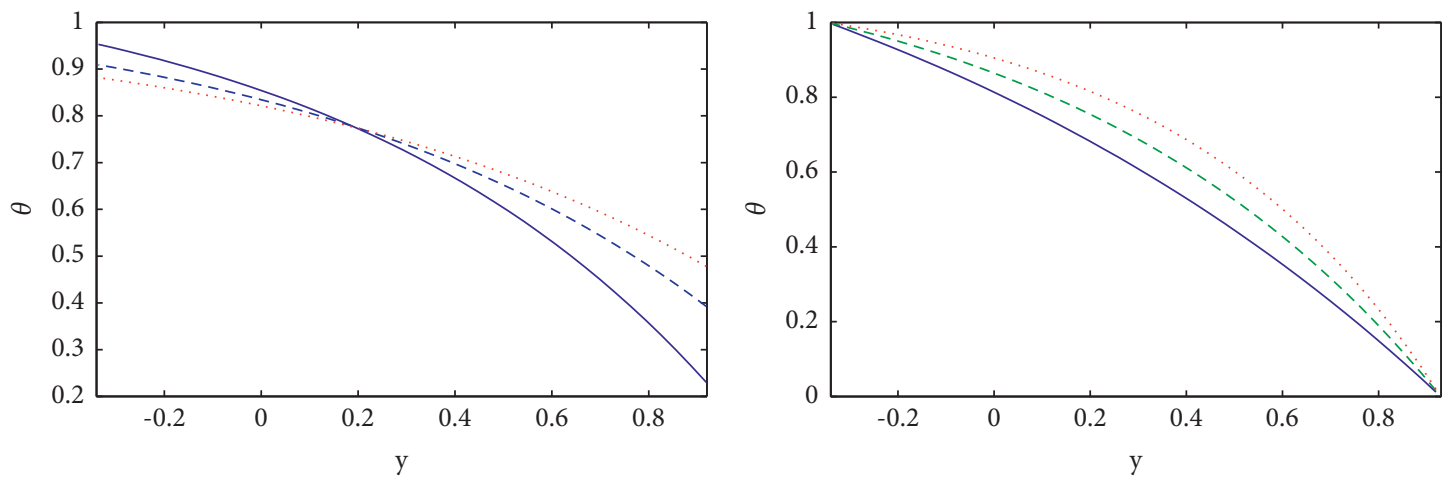

$$
\begin{aligned}
& -\eta_{2}=0.2 \\
& ---\eta_{2}=0.5 \\
& \cdots \cdots \eta_{2}=0.8
\end{aligned}
$$$$
\begin{aligned}
-\mathrm{N}_{\mathrm{b}} & =0.2 \\
--\mathrm{N}_{\mathrm{b}} & =0.6 \\
\cdots \cdots \mathrm{N}_{\mathrm{b}} & =1.0
\end{aligned}
$$

(a)

(b)

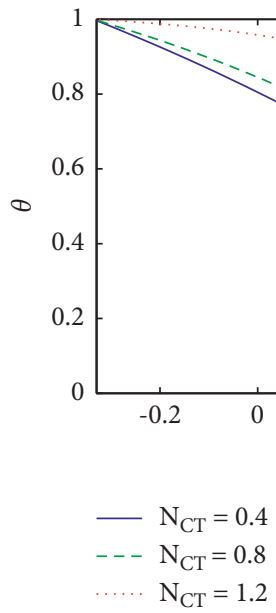

(c)

Figure 4: Impact of temperature on $\eta_{2}, N_{b}$, and $N_{C T}$.

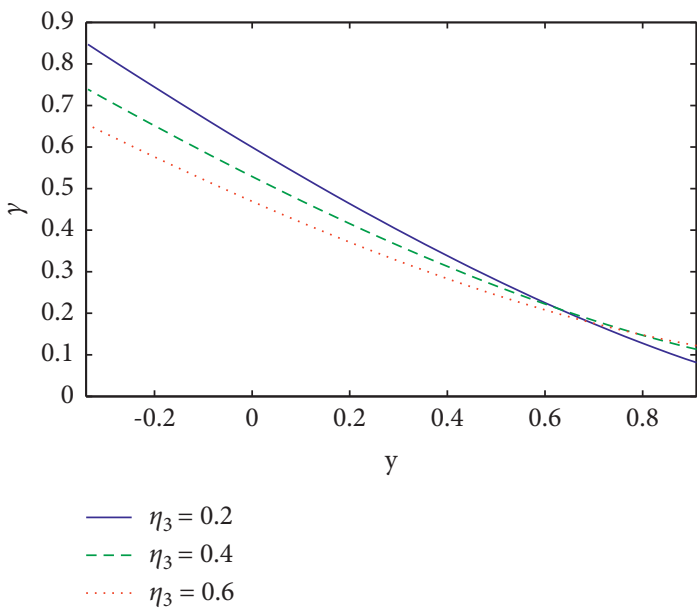

(a)

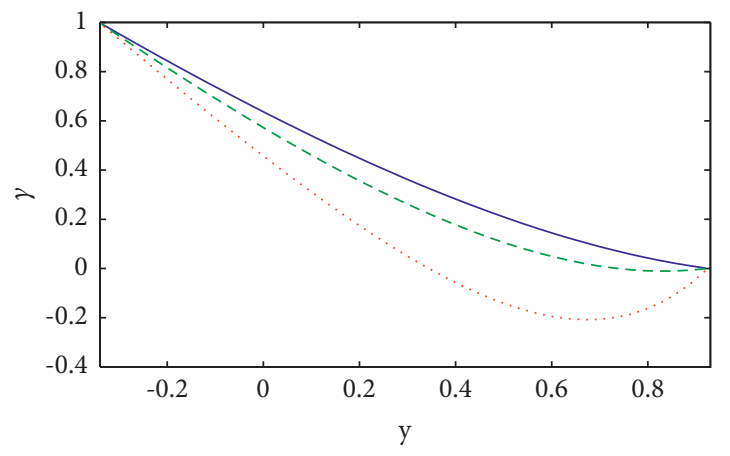

$-\mathrm{N}_{\mathrm{CT}}=0.8$
$---\mathrm{N}_{\mathrm{CT}}=1.0$
$\cdots \cdots \mathrm{N}_{\mathrm{CT}}=1.2$

(b)

FIgURe 5: Continued. 


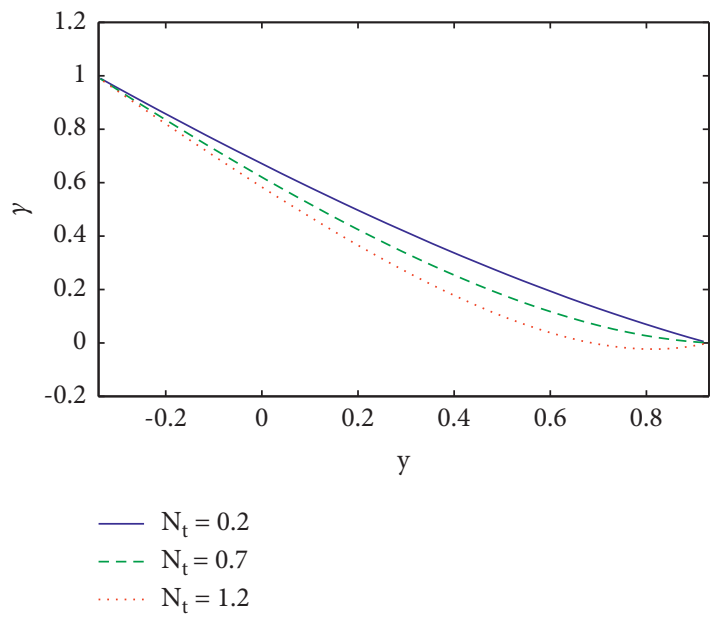

(c)

Figure 5: Impact of concentration on $\eta_{2}, N_{C T}$, and $N_{t}$.
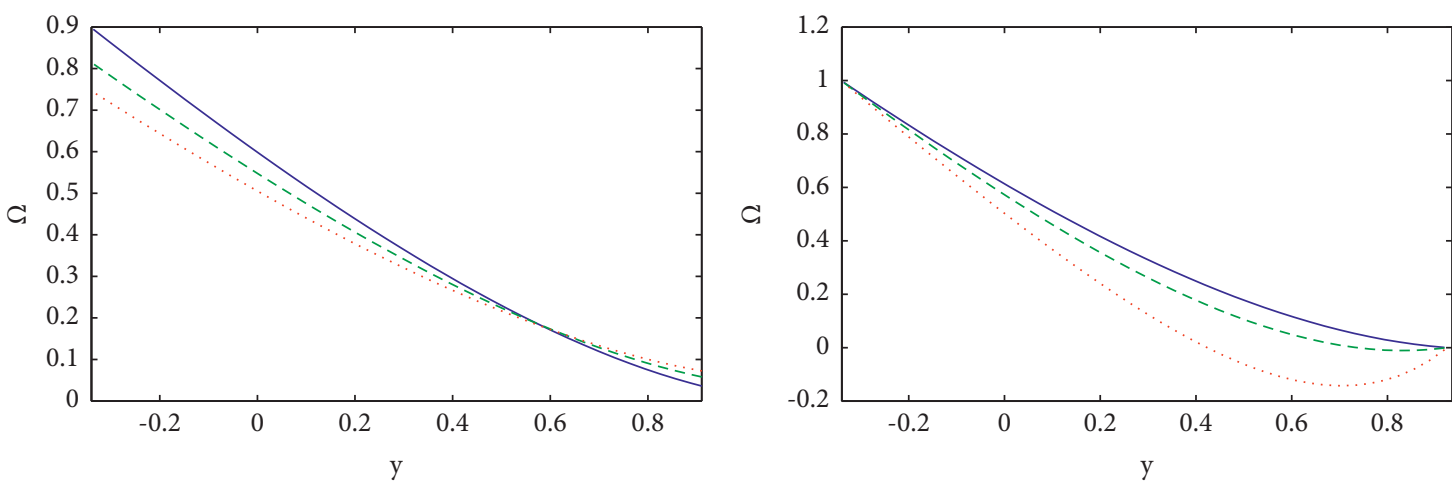

$$
\begin{aligned}
& -\eta_{4}=0.2 \\
& ---\eta_{4}=0.4 \\
& \cdots \cdots \quad \eta_{4}=0.6
\end{aligned}
$$

$-\mathrm{N}_{\mathrm{TC}}=0.8$

- $\mathrm{N}_{\mathrm{TC}}=1.0$

… $\mathrm{N}_{\mathrm{TC}}=1.2$

(a)

(b)

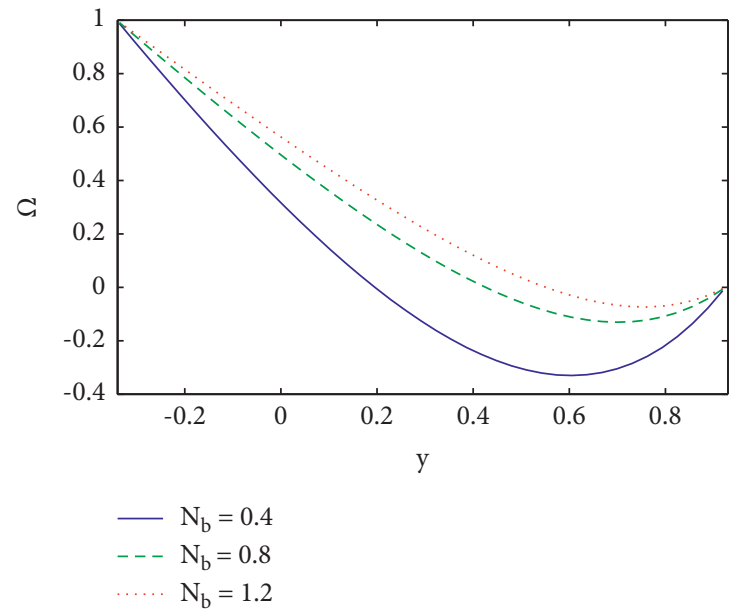

(c)

FIgURE 6: Impact of nanoparticle on $\eta_{4}, N_{T C}$, and $N_{b}$. 

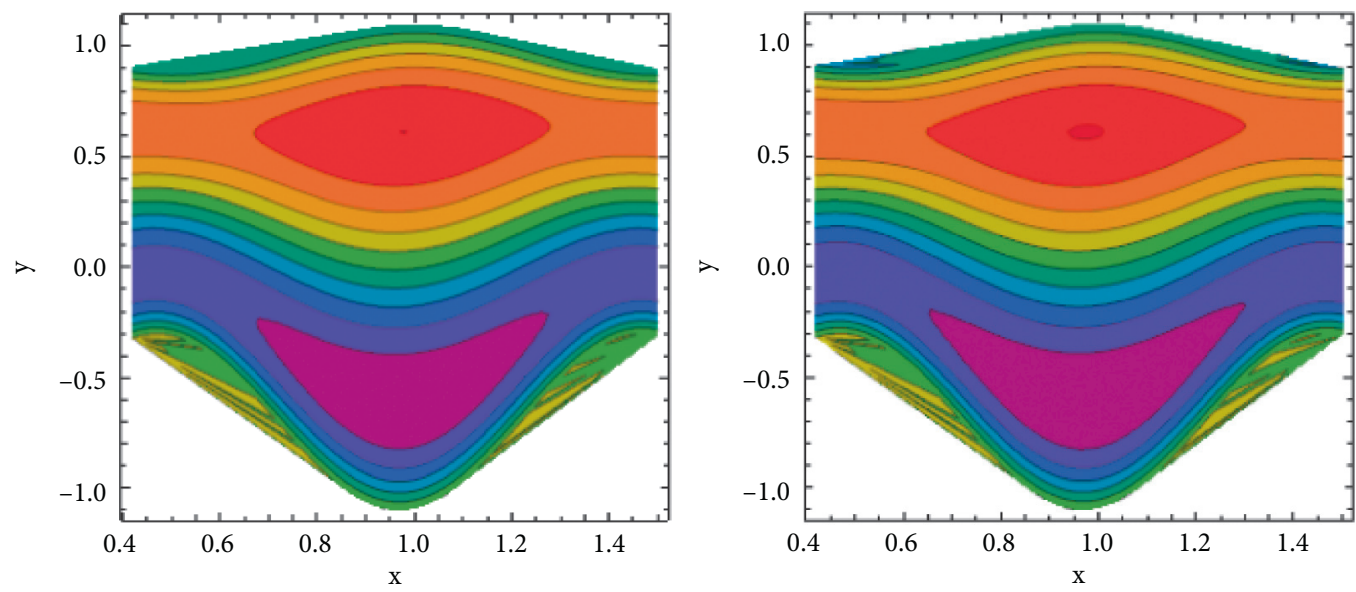

FIGURE 7: Impact of streamlines on $W_{e}$. (a) $W_{e}=0.02$ and (b) $W_{e}=0.04$.
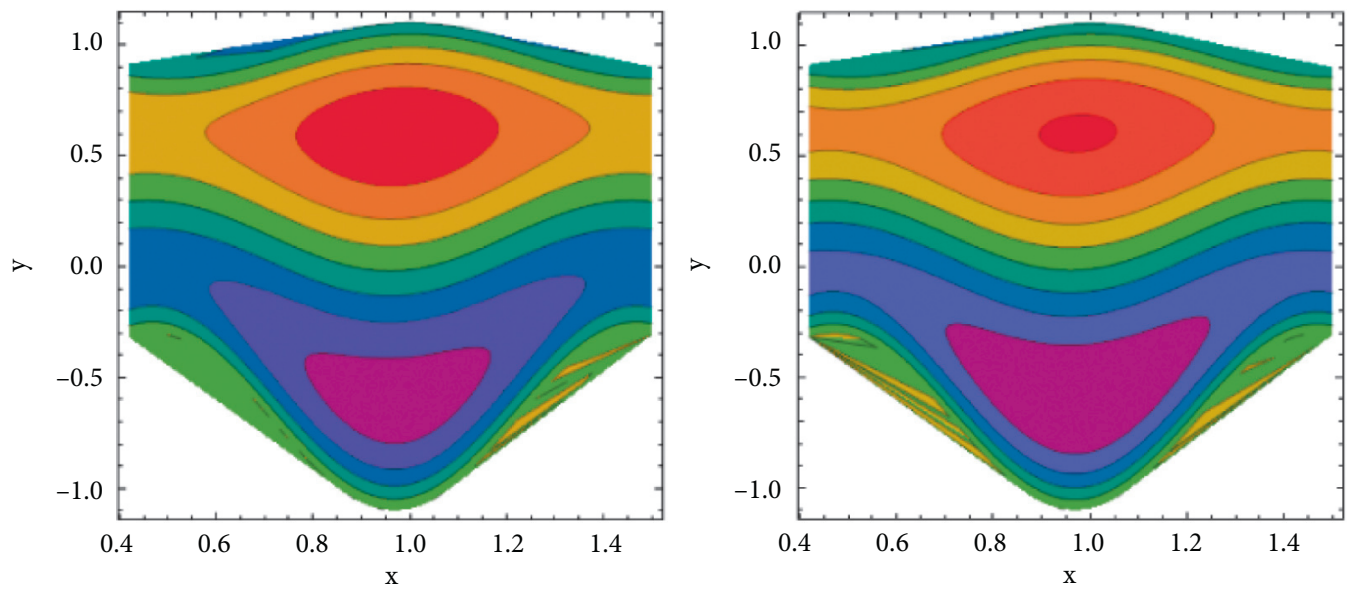

Figure 8: Impact of streamlines on $\beta_{1}$. (a) $\beta_{1}=0.01$ and (b) $\beta_{1}=0.05$.
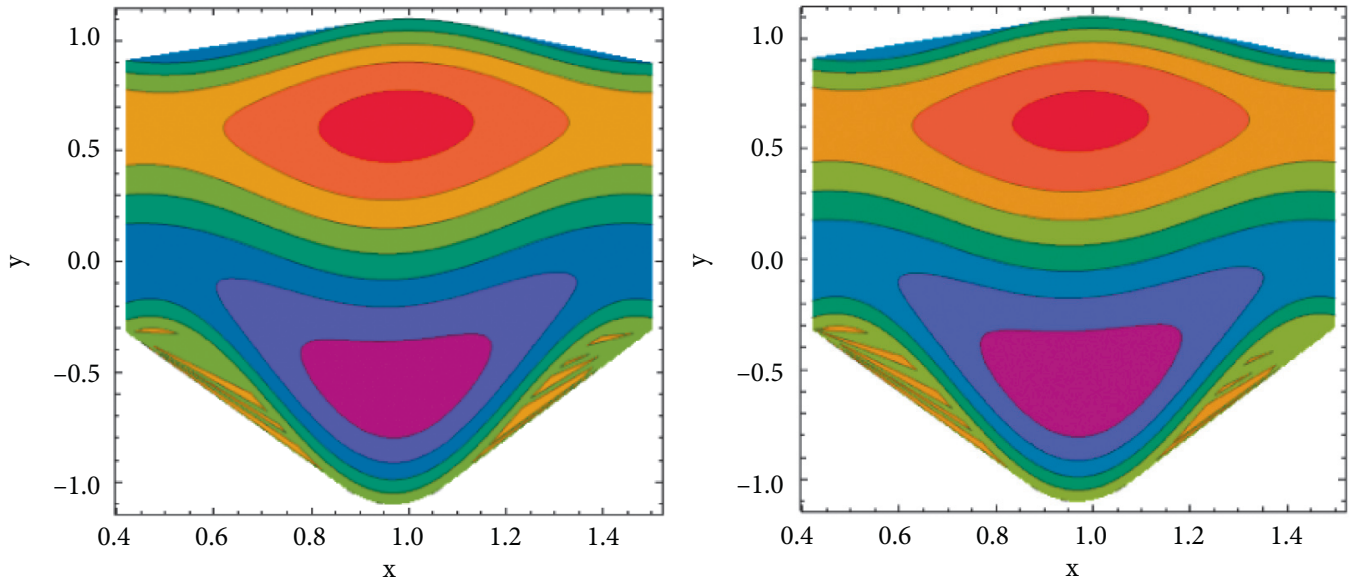

Figure 9: Impact of streamlines on $G_{r t}$. (a) $G_{r t}=1.5$ and (b) $G_{r t}=2.0$.

when the velocity slip parameter $\beta_{1}$ is increased. As illustrated in Figure 8, the size of trapped bolus reduces in the upper half of the channel, whereas the number and size of trapped bolus decrease in the lower half by increasing $\beta_{1}$ values. As the thermal Grashof number rises, the size of the trapped bolus grows larger (see Figure 9), and as the 

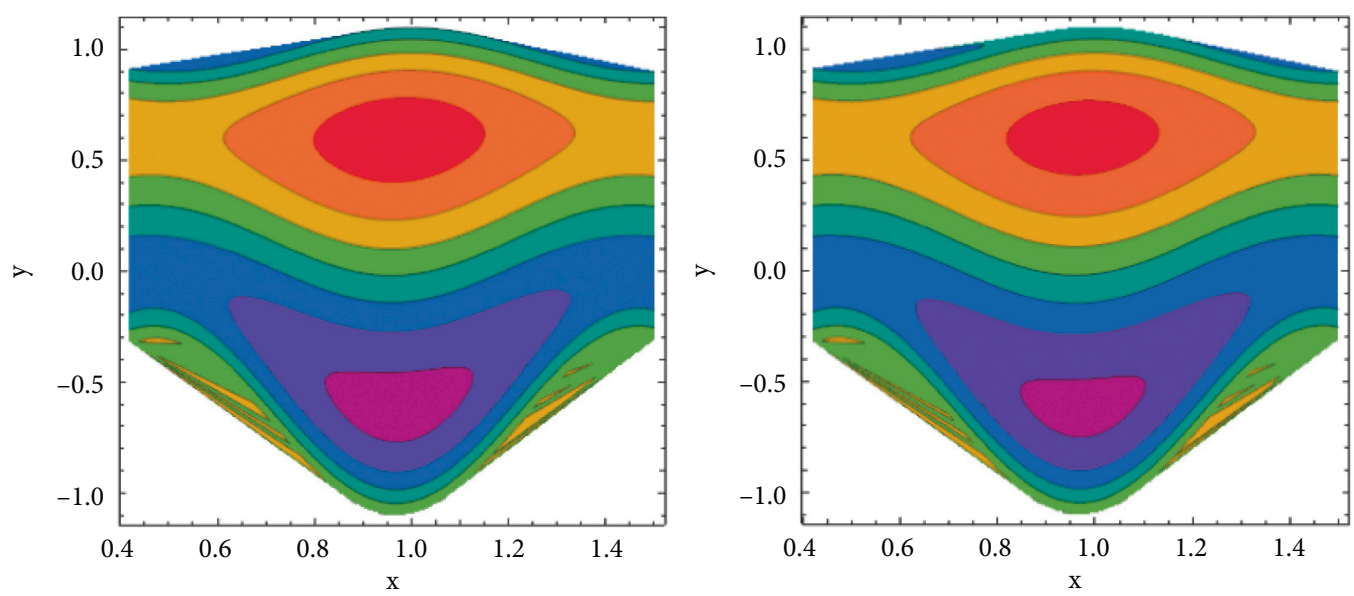

FIgURE 10: Impact of streamlines on $M$. (a) $M=1.5$ and (b) $M=2.0$.

TABLE 1: The comparison of velocity profile with existing literature.

\begin{tabular}{lcc}
\hline$y$ & Present work & Mishra and Rao [5] \\
\hline 0.919093 & -1 & -1 \\
0.796856 & -0.599634 & 0.530207 \\
0.674618 & -0.243748 & -0.18806 \\
0.55238 & 0.0493734 & 0.0434474 \\
0.430142 & 0.261644 & 0.178543 \\
0.307905 & 0.34998 & 0.225119 \\
0.185667 & 0.265135 & 0.185251 \\
0.063429 & 0.054073 & 0.0553249 \\
-0.0588087 & -0.239407 & -0.174226 \\
-0.181046 & -0.596941 & -0.519578 \\
-0.303284 & -1 & -1 \\
\hline
\end{tabular}

Hartmann number rises, the size of the trapped bolus shrinks (see Figure 10). The current study's findings are compared to the existing literature in Table 1.

\section{Conclusions}

The importance of partial slip on double diffusive convection on magneto-Carreau nanofluid in inclined peristaltic asymmetric channel is discussed. The problem is numerically solved. The following is a summary of the main findings from the above analysis:

The velocity drops as the Hartmann number rises, whereas the velocity rises as the Weissenberg number rises

As the velocity slip parameter $\eta_{1}$ is increased, the axial velocity at the center of channel increases

The pressure gradient tends to grow as the thermophoresis parameter, inclination angle, and Weissenberg number increase

The temperature rises as the Brownian motion parameter and the Soret parameter are increased

By increasing the Soret and thermophoresis parameters, the concentration drops
The nanoparticle fraction grows when the Brownian motion parameter is raised, whereas the nanoparticle fraction decreases as the Dufour parameter is increased As the thermal Grashof number rises, the size of the trapped bolus grows larger, and as the Hartmann number rises, the size of the trapped bolus shrinks

\section{Data Availability}

The data used to support the findings of this study are included within the article.

\section{Conflicts of Interest}

The authors declare that they have no conflicts of interest.

\section{Acknowledgments}

The authors extend their appreciation to the Deanship of Scientific Research at King Khalid University, Abha, Saudi Arabia, for funding this work through research groups program under grant number RGP.2/39/42. 


\section{References}

[1] T. W. Latham, "Fluid motion in a peristaltic pump," M.Sc. thesis, MIT, Cambridge, UK, 1966.

[2] C. Pozrikidis, "A study of peristaltic flow," Journal of Fluid Mechanics, vol. 180, no. 1, pp. 515-527, 1987.

[3] O. Eytan, A. J. Jaffa, J. Har-Toov, E. Dalach, and D. Elad, "Dynamics of the intrauterine fluid-wall interface," Annals of Biomedical Engineering, vol. 27, no. 3, pp. 372-379, 1999.

[4] O. Eytan and D. Elad, "Analysis of intra-uterine fluid motion induced by uterine contractions," Bulletin of Mathematical Biology, vol. 61, no. 2, pp. 221-238, 1999.

[5] M. Mishra and A. Ramachandra Rao, "Peristaltic transport of a Newtonian fluid in an asymmetric channel," Zeitschrift für Angewandte Mathematik und Physik (ZAMP), vol. 54, no. 3, pp. 532-550, 2003.

[6] V. K. Stud, G. S. Sephone, and R. K. G. Mishra, "MHD peristaltic flow of a jeffrey fluid in an a symmetric channel with partial slip," Biology Bulletin, vol. 39, pp. 358-390, 1977.

[7] L. M. Srivastava and V. P. Srivastava, Journal of Fluid Mechanics, vol. 122, pp. 439-465, 1984.

[8] V. I. Vishnyakov and K. B. Pavlov, "Peristaltic flow of a conductive liquid in a transverse magnetic field," Magnetohydrodynamics, vol. 8, pp. 174-178, 1972.

[9] K. S. Mekheimer, "Non-linear peristaltic transport of magneto-hydrodynamic flow in an inclined planner channels," Arabian Journal for Science and Engineering, vol. 28, pp. 183-201, 2003.

[10] S. Haider, N. Ijaz, A. Zeeshan, and Y.-Z. Li, "Magneto-hydrodynamics of a solid-liquid two-phase fluid in rotating channel due to peristaltic wavy movement," International Journal of Numerical Methods for Heat and Fluid Flow, vol. 30, no. 5, pp. 2501-2516, 2019.

[11] O. Eytan and E. David, "Analysis of intra-uterine fluid motion induced by uterine contractions," Bulletin of Mathematical Biology, vol. 61, no. 2, pp. 221-238, 1999.

[12] K. S. Mekheimer, "Effect of the induced magnetic field on peristaltic flow of a couple stress fluid," Physics Letters A, vol. 372, no. 23, pp. 4271-4278, 2008.

[13] S. U. Choi, "Enhancing thermal conductivity of fluid with nanoparticles.developments and Applications of non-Newtonian Flow," ASME FED, vol. 66, no. 231, pp. 99-105.

[14] S. U. S. Choi, Z. G. Zhang, W. Yu, F. E. Lockwood, and E. A. Grulke, "Anomalous thermal conductivity enhancement in nanotube suspensions," Applied Physics Letters, vol. 79, no. 14 , pp. $2252-2254,2001$.

[15] H. Masuda, A. Ebata, K. Teramae, and N. Hishinuma, "Alteration of thermal conductivity and viscosity of liquid by dispersing ultra-fine particles. Dispersion of $\mathrm{Al} 2 \mathrm{O} 3, \mathrm{SiO} 2$ and TiO2 ultra-fine particles," Netsu Bussei, vol. 7, no. 4, pp. 227-233, 1993.

[16] S. Lee, S. U.-S. Choi, S. Li, and J. A. Eastman, "Measuring thermal conductivity of fluids containing oxide nanoparticles," Journal of Heat Transfer, vol. 121, no. 2, pp. 280-289, 1999.

[17] Y. Xuan and Q. Li, "Heat transfer enhancement of nanofluids," International Journal of Heat and Fluid Flow, vol. 21, no. 1, pp. 58-64, 2000.

[18] Y. Xuan and W. Roetzel, "Conceptions for heat transfer correlation of nanofluids," International Journal of Heat and Mass Transfer, vol. 43, no. 19, pp. 3701-3707, 2000.

[19] M. Kothandapani and J. Prakash, "Effects of thermal radiation parameter and magnetic field on the peristaltic motion of Williamson nanofluids in a tapered asymmetric channel,"
International Journal of Heat and Mass Transfer, vol. 81, pp. 234-245, 2015.

[20] S. Akram, F. Afzal, and Q. Afzal, "Impact of nanofluids and magnetic field on the peristaltic transport of a couple stress fluid in an asymmetric channel with different wave forms," Thermal Science, vol. 24, no. 2, pp. 1407-1422, 2020.

[21] D. A. Nield and A. V. Kuznetsov, "The Cheng-Minkowycz problem for natural convective boundary-layer flow in a porous medium saturated by a nanofluid," International Journal of Heat and Mass Transfer, vol. 52, no. 25-26, pp. 5792-5795, 2009.

[22] R. E. Abo-Elkhair, M. M. Bhatti, and K. S. Mekheimer, "Magnetic force effects on peristaltic transport of hybrid bionanofluid ( $\mathrm{Au} \mathrm{Cu}$ nanoparticles) with moderate Reynolds number: an expanding horizon," International Communications in Heat and Mass Transfer, vol. 123, Article ID 105228, 2021.

[23] M. M. Bhatti, "Biologically inspired intra-uterine nanofluid flow under the suspension of magnetized gold (Au) nanoparticles: applications in nanomedicine," Inventions, vol. 6, no. 2, p. 28, 2021.

[24] S. Akram, M. Zafar, and S. Nadeem, "Peristaltic transport of a Jeffrey fluid with double-diffusive convection in nanofluids in the presence of inclined magnetic field," International Journal of Geometric Methods in Modern Physics, vol. 15, no. 11, Article ID 1850181, 2018.

[25] N. S. Akbar and M. B. Habib, "Peristaltic pumping with double diffusive natural convective nanofluid in a lopsided channel with accounting thermophoresis and Brownian moment," Microsystem Technologies, vol. 25, no. 4, pp. 1217-1226, 2019.

[26] B. Anwar and D. Tripathi, "Mathematica simulation of peristaltic pumping with double-diffusive convection in nanofluids a bio-nanoengineering model," Proceedings of the Institution of Mechanical Engineers, Part N: Journal of Nanomaterials, Nanoengineering and Nanosystems, vol. 225, pp. 99-114, 2012.

[27] S. K. Asha and G. Sunitha, "Thermal radiation and hall effects on peristaltic blood flow with double diffusion in the presence of nanoparticles," Case Studies in Thermal Engineering, vol. 17, Article ID 100560, 2020.

[28] S. Akram, M. Athar, K. Saeed, and M. Y. Umair, "Doublediffusivity convection on Powell-Eyring nanofluids in nonuniform inclined channel under the impact of peristaltic propulsion and induced magnetic field," The European Physical Journal Plus, vol. 136, no. 5, p. 494, 2021.

[29] A. Sharma, D. Tripathi, R. K. Sharma, and A. K. Tiwari, "Analysis of double diffusive convection in electroosmosis regulated peristaltic transport of nanofluids," Physica A: Statistical Mechanics and Its Applications, vol. 535, Article ID 122148, 2019.

[30] A. Yoshimura and R. K. Prud'homme, "Wall slip corrections for Couette and parallel disk viscometers," Journal of Rheology, vol. 32, no. 1, pp. 53-67, 1988.

[31] L. M. H. Navier, "Sur les lois du mouvement des fluids," Comptes Rendus des Seances de l'Academie des Sciences, vol. 6, pp. 389-440, 1827.

[32] X. Mandviwalla and R. Archer, "The influence of slip boundary conditions on peristaltic pumping in a rectangular channel," Journal of Fluids Engineering, vol. 130, Article ID 124501, 2008.

[33] K. Vajravelu, S. Sreenadh, and R. Saravana, "Combined influence of velocity slip, temperature and concentration jump conditions on MHD peristaltic transport of a Carreau fluid in 
a non-uniform channel," Applied Mathematics and Computation, vol. 225, pp. 656-676, 2013.

[34] R. Ellahi, F. Hussain, F. Ishtiaq, and A. Hussain, "Peristaltic transport of Jeffrey fluid in a rectangular duct through a porous medium under the effect of partial slip: an application to upgrade industrial sieves/filters," Pramana, vol. 93, no. 3, p. $34,2019$.

[35] E. H. Aly and A. Ebaid, "Exact analytical solution for the peristaltic flow of nanofluids in an asymmetric channel with slip effect of the velocity, temperature and concentration," Journal of Mechanics, vol. 30, no. 4, pp. 411-422, 2014.

[36] S. Srinivas, R. Gayathri, and M. Kothandapani, "The influence of slip conditions, wall properties and heat transfer on MHD peristaltic transport," Computer Physics Communications, vol. 180, no. 11, pp. 2115-2122, 2009. 